\title{
Changes in county-scale landscape patterns in northern Fujian Province
}

\author{
Xuncheng Fan ${ }^{*}$ \\ College of Urban and Rural Construction, Shaoyang University, Shaoyang, 422000, China
}

\begin{abstract}
Based on the five-phase Landsat TM/ETM remote sensing image data, the remote sensing images were processed and the landscape pattern indices were calculated with the help of ENVI and FRAGSTATS software, respectively. Jian'ou city, a large agricultural city in northern Fujian Province, was used as a county-scale study case to explore its landscape pattern changes during the 20-year period from 1995 to 2015. The results show that the development intensity of Jian'ou city increased continuously from 1995 to 2010, the fragmentation of the landscape increased, the degree of aggregation decreased significantly, and the landscape structure became increasingly complex. After 2010, the landscape connectivity gradually became better, the degree of aggregation increased, and the landscape structure tended to be simpler.
\end{abstract}

\section{Introduction}

Landscape pattern is formed by nature or by man. It is the result of a series of landscape elements of different sizes and shapes, arranged in different ways. It is also the result of a complex interaction of physical, biological and social factors [1-2]. Landscape pattern is the study of energy and functional flows between landscape elements in an ecosystem, and land use changes will alter the functional and energy flows of the landscape pattern [3]. Therefore, landscape pattern is the result of land use change. Remote sensing, Geographic Information System and computer technologies have been widely used to quantify landscape patterns. The quantification of spatial patterns using landscape indices is the basic element of this research model [4]. In recent years, domestic scholars have done a lot of resea ${ }^{1} \mathrm{rch}$ on landscape patterns. For example, Xiao et al. [3] studied the landscape pattern changes in the western suburbs of Shenyang using four landscape pattern indices. He et al. [5] studied the land use landscape pattern changes in the Beijing-Tianjin-Hebei metropolitan area based on a coupled Logistic-CA-Markov model, and conducted a multi-scenario simulation of future change trends. Su et al. [6] explored the relationship between landscape pattern and ecological processes and the influence on the value of ecosystem services. Wang et al. [7] explored the landscape pattern changes and the impact on ecosystem service values in Mapo Town, Beijing fringe area, and found that the landscape fragmentation increased significantly during the study period, but the ecosystem service values were not significantly affected. Instead, reasonable planning and policy protection led to a

\footnotetext{
*Corresponding author: xunchengfan@126.com
}

significant increase in ecosystem service values during the study period. Li et al. [8] evaluated the landscape ecological security of the Ningjiang River Basin in three dimensions: natural, human-social and landscape pattern, and found that the landscape ecological risk in the study area was high. The connectivity of the landscape can be significantly improved by constructing ecological corridors. Lou et al. [9] constructed an ecological risk evaluation model for Aha Lake National Wetland Park based on the landscape index and evaluated its landscape ecological risk for the past 9 years from 2009 to 2017, and found that the main cause of the increased landscape ecological risk in the study area was interference from human activities. The above research has laid a solid foundation for the study of landscape pattern at the county scale.

In recent years, with the continuous economic development, the level of urbanization of counties has been increasing, and the landscape pattern of counties has also been changing. An investigation of the evolution pattern of landscape pattern of counties can provide reference for the subsequent rational use and scientific planning of land in counties. Therefore, this paper takes Jian'ou city (a county-level city) as the research object. The city is a large agricultural city in northern Fujian Province, as well as a provincial ecological city and provincial garden city. Based on the land use classification data, the change of landscape pattern in Jian'ou city between 1995 and 2015 is analyzed in order to provide reference for the scientific land use in Jian'ou city and the surrounding counties.

\section{Overview of the study area}

Jian'ou city belongs to the area under Nanping City, Fujian Province (Figure 1), is the largest county-level city 
in Fujian Province, with a total land area of $4233 \mathrm{~km}^{2}$. It belongs to the low mountainous hilly area along the southeast coast, with mountains accounting for $57.3 \%$ of the total land area and 91 peaks above 1,000 meters. The rivers in the territory are fully developed and belong to Jianxi basin of Minjiang River, with a total length of $1079 \mathrm{~km}$. Jian'ou has a beautiful ecology and pleasant climate, belonging to subtropical maritime monsoon climate. The annual average temperature is $19^{\circ} \mathrm{C}$ and the rainfall is $1673 \mathrm{~mm}$. Jian'ou is rich in products, bamboo, wood and other agricultural and forestry resources in the province and the country's forefront. Forest coverage rate of $79.8 \%$, is the national key forestry county (city). The area of moso bamboo, the number of standing bamboo, bamboo timber and fresh bamboo shoots production in the country first, was named "Jian'ou bamboo shoots Chinese characteristic agricultural products advantageous area" and "national organic bamboo shoots product certification demonstration creation area (city)". At the same time, it is also the county (city) with the largest grain sowing area and the highest commodity rate among the 16 "national commodity grain base counties (cities)"in Fujian. By the end of 2019, the resident population was $12.30 \times 10^{4}$, the most populous county-level city in northern Fujian, with a regional gross domestic product (regional GDP) of $81.54 \times 10^{8}$ yuan. In 2020, the total general public budget revenue was 14.78 billion yuan, an increase of $0.6 \%$, and the local general public budget revenue was 10.58 billion yuan, an increase of $5.9 \%$.

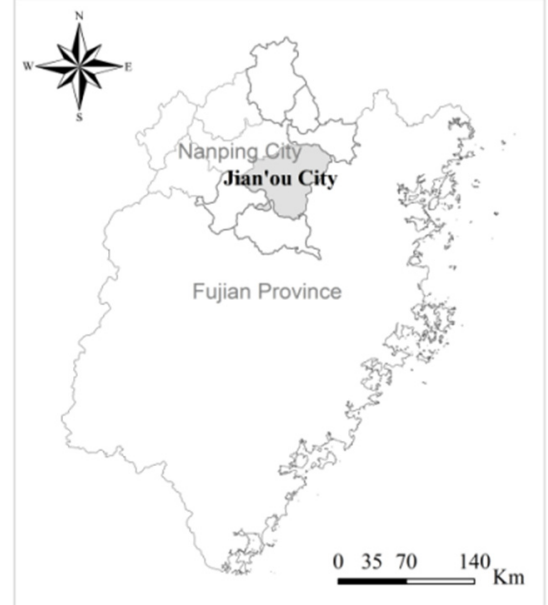

Figure 1. Map of the study area.

\section{Research Methodology}

The base data were obtained from the 5 phases of remote sensing images downloaded from the geospatial data cloud and the remote sensing images were processed. The land use types in the study area were classified into 6 categories with reference to the "Classification of Land Use Status" (GB/T 21010-2007) released by China in 2007. With the help of FRAGSTATS 4.2 software, the landscape pattern of Jian'ou city was analyzed at the landscape level. In this study, three landscape pattern indices at the landscape level were selected [10-12] and the formulae were calculated as follows.
(1) Landscape patch density $(P D)$. It indicates the number of patches on a unit area. Its mathematical expression is as follows.

$$
P D=\frac{n}{A} \times 100
$$

Where $n, P D$ and $A$ denote the total number of patches of each type in the landscape, the total area of the landscape and the density of patches in the landscape, respectively, in units of patches $/ 100 \mathrm{hm}^{2}$.

(2) Contagion index (CONTAG). It indicates the degree of aggregation of each patch type in the landscape. Its formula is as follows.

CONTAG $=\left[1+\frac{\sum_{i=1}^{m} \sum_{k=1}^{m}\left(p_{i} \frac{g_{i k}}{\sum_{k=1}^{m} g_{i k}}\right) \ln \left(p \frac{g_{i k}}{\sum_{k=1}^{m} g_{i k}}\right)}{2 \ln m}\right] \times 100$

Where $P_{i}, g_{i k}$ and $m$ represent the percentage of the total landscape area occupied by patch type $i$, the number of adjacent grids between patch types and the total number of patch types, respectively, the same below.

(3) Patch shape index $(S H A P E)$. It indicates the complexity of the landscape shape, which is defined by using the deviation of the specified patch shape from a square or circle. Its calculation formula is as follows.

$$
\text { SHAPE }=\frac{0.25 E}{\sqrt{A}}
$$

where $E$ is the total length of all patch boundaries in the landscape. $A$ is the total area of the landscape. The larger the $S H A P E$, the more complex the patch shape in the landscape.

(4) Shannon Diversity Index $(S H D I)$. It refers to the complexity of the structure of the landscape system, and its mathematical model is as follows.

$$
S H D I=-\sum_{i=1}^{m}\left[P_{i} \ln P_{i}\right]
$$

A larger SHAPE indicates a more complex patch shape in the landscape.

\section{Results and Analysis}

\subsection{Variation of landscape patch density}

From the $P D$ index of Figure 2, it can be seen that the $P D$ index of Jian'ou city has changed significantly in all time periods. Between 1995 and 2010, the $P D$ index increased continuously and reached a peak in 2010 at 4.0708 . It indicates that compared with other years, Jian'ou city was the most developed and the landscape was the most fragmented in 2010. After 2010, the $P D$ index value decreased sharply, indicating that the the number of patches in the county decreased significantly during this period, and the landscape connectivity became better. 


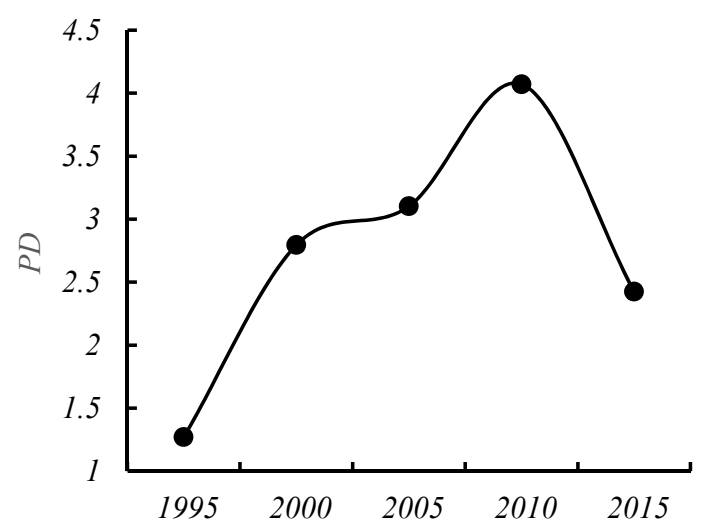

Figure 2. Changes of $P D$ index from 1995 to 2015.

\subsection{Change in Contagion index}

From the contagion index (CONTAG) (Figure 3), the CONTAG index of Jian'ou city showed an inverted " $\sqrt{ }$ curve trend of decreasing and then increasing during the 20 years from 1995 to 2015 . From each time period, the value of CONTAG index is the largest in 1995, at 65.659, and the lowest in 2010, at 56.596. It starts to increase again in the next 5 years, and its value remains similar to that of 2000 , at 62.166 . It indicates that due to the continuous development of economy, the degree of landscape aggregation decreases and fragmentation is serious after 1995 in Jian'ou city. In contrast, after 2010, the degree of aggregation of patch types in the landscape of Jian'ou city continued to increase, which is inseparable from the government's continuous land consolidation and intensive land use.

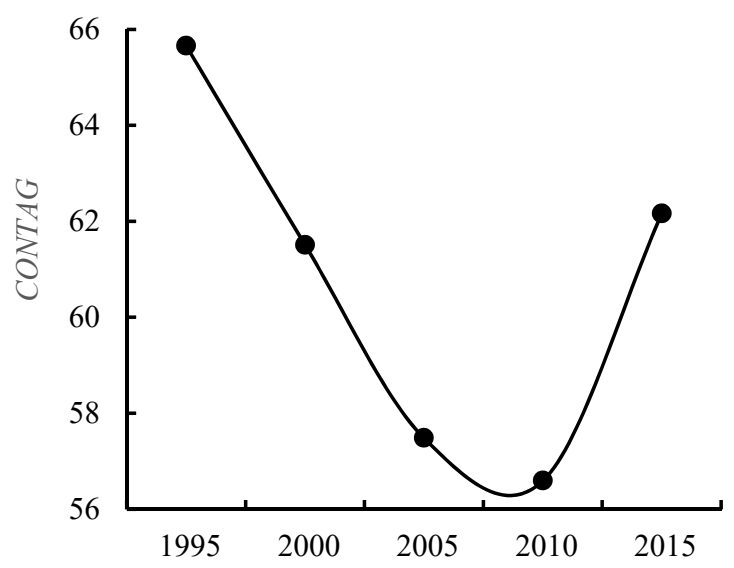

Figure 3. Changes of CONTAG index from 1995 to 2015.

\subsection{Change in patch shape index}

The change in the SHAPE index from 1995 to 2015 in Jian'ou County (Figure 4) shows that fluctuations were more pronounced during the study period. Higher values of the patch shape index indicate higher complexity of the patch types. Jian'ou city showed a peak in 2005, indicating that this city had the most complex patch types during this time period. In contrast, the lowest SHAPE value was found in 2010 , indicating that the complexity of the patch types was lowest in this time period, and the patch types were regular and simple.

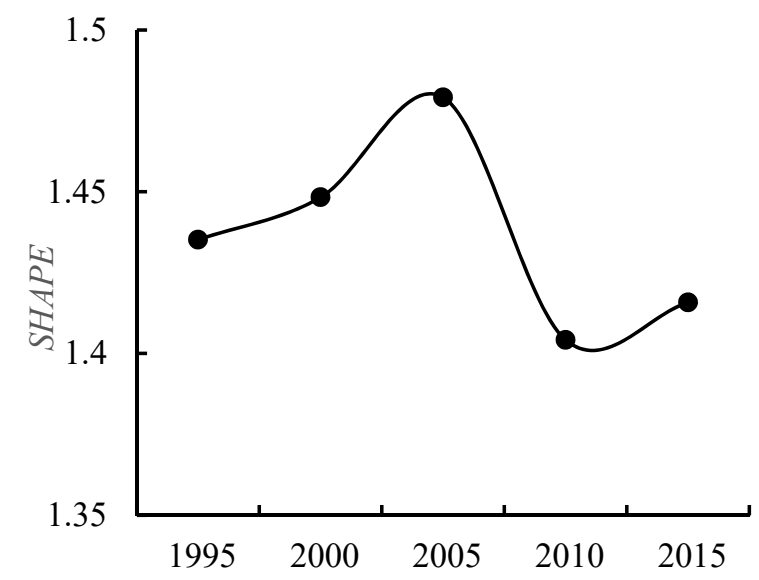

Figure 4. Changes in SHAPE index from 1995 to 2015.

\subsection{Variation of Shannon Diversity Index}

From the change of SHDI in Jian'ou city (Figure 5), in general, the value of $S H D I$ tends to increase first and then decrease. From different time periods, the SHDI value of was the largest Jian'ou cityin 2010, which was 1.4251 , indicating that the structure of landscape system gradually became complex from 1995 to 2010 compared with other time periods. After 2010, the SHDI value of Jian'ou city started to decrease, indicating that the structure of landscape gradually became simpler between 2010 and 2015.

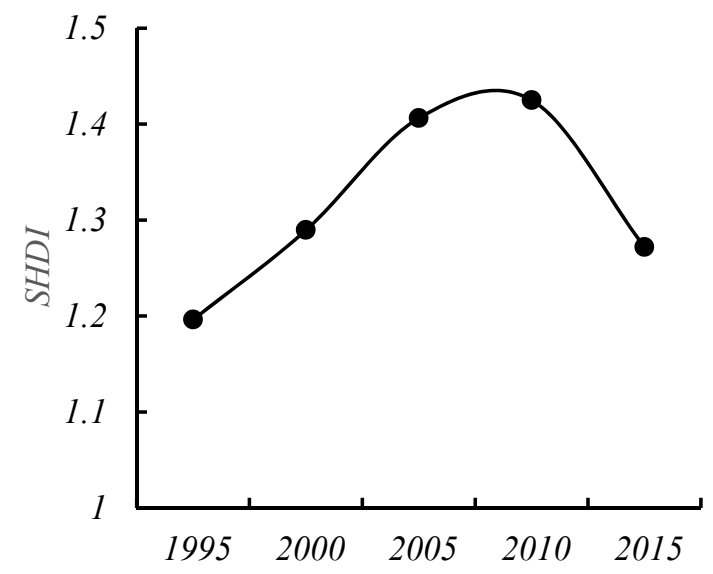

Figure 5. Changes of SHDI index from 1995 to 2015.

\section{Conclusion}

Based on the five phases of remote sensing image data, RS and GIS technologies were used to interpret, classify and calculate the landscape index of remote sensing images with the help of ENVI and FRAGSTATS software. The changes of landscape pattern in Jian'ou city between 1995 and 2015 were analyzed. The results showed that the $P D$ index of Jian'ou city changed significantly during the study period, with the greatest development intensity and the most fragmented landscape in 2010. After 2010, the landscape connectivity gradually became better. The CONTAG index showed an inverted " $\sqrt{ }$ " curve trend of 
decreasing first and then increasing. The aggregation of patch types in the landscape has been increasing since 2010. SHAPE showed a peak in 2005, indicating that had the most complex patch types during this time period in Jian'ou city. The SHDI values show a trend of increasing and then decreasing. Between 1995 and 2010, the structure of the landscape system in Jian'ou city has become increasingly complex. And after 2010, the structure of the landscape has gradually become simple in Jian'ou city.

\section{Acknowledgments}

This work was supported by the Education Department of Hunan Province (No.19C1670), and the Specialized Research Fund for the Doctoral Program of Shaoyang University (No. 17ZX03).

\section{References}

1. W.B. Chen, D.N. Xiao, X.Z. Li. Study on the classification, application and construction of landscape index. Journal of Applied Ecology 121 (2002).

2. R.M. Hulshoff. Landscape indices describing a Dutch landscape. Landscape ecology 10, 101 (1995).

3. D.N. Xiao, Y. Zhao, Z.W. Sun, G.S. Zhang. A study of landscape pattern changes in the western suburbs of Shenyang. Journal of Applied Ecology 75 (1990).

4. R.V. O'Neill, K.H. Riitters, J.D. Wickham, K. Bruce Jones. Landscape Pattern Metrics and Regional Assessment. Ecosystem Health 5, 225 (2001).

5. D. He, F.J. Jin, J. Zhou. Land use landscape pattern change based on Logistic-CA-Markov: taking
Beijing-Tianjin-Hebei metropolitan area as an example. Geoscience 31, 903 (2011).

6. C.H. Su, B.J. Fu. The relationship between landscape patterns and ecological processes and their effects on ecosystem services. Journal of Nature 34, 277 (2012).

7. L.Q. Wang, Z.Q. Zhang, G. Li, F.W. Ma ,L.X. Chen. Evaluation of landscape pattern changes and impacts on ecosystem services in the marginal areas of Beijing: taking Niulanshan, Mapo town as an example. Journal of Ecology 38, 750 (2018).

8. Q.P. Li, Z.D. Zhang, L.W. Wan, C.X. Yang, J. Zhang, C. Ye, Y.C. Chen. Landscape pattern optimization of Ningjiang River basin based on landscape ecological risk assessment. Journal of Geography 74, 1420 (2019).

9. N. Lou, Z.J. Wang, S.T. He. Landscape ecological risk assessment of Aha Lake National Wetland Park based on landscape pattern. Soil and Water Conservation Research 27, 233 (2020).

10. Y.N. Liu, L.Q. Kong, Y. Xiao, H. Zheng. Relationship between landscape patterns and ecosystem water purification services in the Yangtze River basin. Journal of Ecology 39, 844 (2019).

11. Y.Y. Zhang, X.B. Cai, C. Yang, X.X. Song, R.D. Li, E.H. Li, X.L. Wang.Evolution of landscape pattern and analysis of driving forces in Honghu Wetland Nature Reserve from 1974 to 2017. Lake Science 31, 171 (2019).

12. J. Peng, D.N. Lv, J.Q. Dong, Y.X. Liu, Q.Y. Liu, B. Li. Process coupling and spatial integration: a landscape ecological cognition of ecological restoration in national land space. Journal of Natural Resources 35, 3 (2020). 